\title{
The Mechanical Properties of Chelyabinsk LL5 Chondrite Under Compression and Tension
}

\author{
Dmitry Zaytsev ${ }^{1,2} \cdot$ Elijah N. Borodin $^{3}$ (D) A. E. Dudorov ${ }^{4} \cdot$ P. Panfilov ${ }^{1}$
}

Received: 17 December 2018 / Accepted: 9 February 2021 / Published online: 27 February 2021

(c) The Author(s) 2021

\begin{abstract}
The mechanical properties of Chelyabinsk LL5 chondrite (Chelyabinsk meteorite) were studied by uniaxial compression and diametral compression/indirect tension test. Twenty cylindrical samples, 10 for compression and 10 for tension, with the diameter $3.3 \mathrm{~mm}$ and $1.65 \mathrm{~mm}$ in height have been prepared for testing. It was shown that the strength of the tested samples under compression almost 45 times greater than it is at tension: $372 \pm 10 \mathrm{MPa}$ and $8.2 \pm 0.7 \mathrm{MPa}$, respectively. Fracture behaviour under compression and tension was similar and can be characterised as brittle. The obtained compression strength of the Chelyabinsk meteorite lies close to the maximal values of strength for many other chondrites, whereas its tensile strength magnitude resides in the bottom quarter of the range of similar measurements. It may be caused by the small sizes of the investigated samples together with a large number of tiny cracks between the grains in the Chelyabinsk chondrite. Our estimations have shown that if one assumes that the initial shape of the Chelyabinsk fireball was spherical or ellipsoidal, then its fragmentation stress is close to the experimental tensile strength and much lower than the compression strength. Hence, a stress state equivalent to one appearing at the indirect tension test could occur in the Chelyabinsk fireball during its fall in the Earth atmosphere.
\end{abstract}

Keywords Chelyabinsk meteorite $\cdot$ Chondrite $\cdot$ Uniaxial compression test $\cdot$ Indirect tension test $\cdot$ Strength $\cdot$ Brittle fracture $\cdot$ Microstructure $\cdot$ Mechanical properties

Dmitry Zaytsev

Dmitry.Zaytsev@urfu.ru

Elijah N. Borodin

elbor7@gmail.com

1 Institute of Natural Sciences and Mathematics, Ural Federal University, 620002 Mira str., 19, Ekaterinburg, Russia

2 The Institute of High Temperature Electrochemistry of the Ural Branch of the Russian Academy of Sciences, st. Akademicheskaya, 20, 620137 Yekaterinburg, Russian Federation

3 Mechanics and Physics of Solids Research Group, Department of MACE, The University of Manchester, M13 9PL Manchester, UK

4 Department of Physics, Chelyabinsk State University, 454001 Br. Kashirinykh str., 129, Chelyabinsk, Russia 


\section{Introduction}

The Chelyabinsk meteorite fell in the Chelyabinsk region of Russia on February 15, 2013, at 03:20 Universal Time and still attracts significant attention of scientific community (Gorkavyi et al. 2019). A large number of different fragments of the Chelyabinsk have been studied to date (Gorkavyi et al. 2019; Flynn et al. 2018; Morlok et al. 2017; Kaeter et al. 2017; Righter et al. 2015; Kohout et al. 2014; Galimov et al. 2013). These studies reveal that Chelyabinsk is a monomict LL5 breccia with a complex bombardment history. At least three distinct predominant lithologies were revealed: light (main), dark (shocked) (Galimov et al. 2013) and fully shock-molten components (Righter et al. 2015; Morlok et al. 2017). According to Galimov et al. (2013), the Chelyabinsk meteorite contains roughly one-third of shock-melted material, which composition is similar to the composition of the major part. Other recent work has focussed on the comparison of Chelyabinsk with other meteorites (Gorkavyi et al. 2019; Flynn et al. 2018), refinement of its fall trajectory (Buhl and Wimmer 2013), a search of sources of its cosmic origin and discovering new ways to protect people from asteroidal hazards (Dudorov et al. 2016; Popova et al. 2013; Emel'yanenko et al. 2013; Grygorian et al. 2013; Borovicka et al. 2013). Despite the considerable attention attracted to the Chelyabinsk meteorite, the data about its mechanical properties are not sufficient to date as it usually requires a strong multidisciplinary collaboration of astronomers, mechanicians and material scientists. Another considerable obstacle is the requirement for manufacturing small-sized samples suitable for mechanical testing. It is equally challenging to select representative samples of the meteorite with regard to mechanical properties (e.g., crack density) and to then manufacture small sub-samples for testing without compromising their structural integrity. In one of the first works, where the mechanical properties of the Chelyabinsk were subjected to study (Popova et al. 2013), the most of fragments composed of relatively small pieces contain a large number of cracks (Popova et al. 2013). It has been shown that the compression strength of the cuboid samples $(10 \times 10 \mathrm{~mm}$ and $20 \mathrm{~mm}$ in height), which was cut from the fragment of the Chelyabinsk, was 64.0 MPa, that is quite low for chondrites (Flynn et al. 2018).

The compression tests of other ordinary chondrite meteorites were carried out by many researchers (Kimbereley and Ramesh 2011; Flynn et al. 2018). Ordinary chondrite compression strengths were in the range of 50-500 MPa (Popova et al. 2013; Kimbereley and Ramesh 2011; Flynn et al. 2018). On the other hand, there is extremely little information about the strength properties of these materials under tension. It seems obvious that the direct tension test of such brittle materials is impossible. Therefore, the diametral compression test or Brazilian disk test (Yuan and Shen 2017) is commonly used to study the tensile properties of ordinary chondrite meteorites. According to Morgan et al. (2015) tensile strength of ordinary chondrites was $36 \mathrm{MPa}$. The stony meteorites have compressive strength $217 \pm 134 \mathrm{MPa}$ and tensile strength of $30 \pm 17 \mathrm{MPa}$ for the samples recovered on the ground (Svetsov et al. 1995; Tsvetkov and Skripnik 1991; Popova et al. 2011).

There is a large scatter, with a variance of $50 \%$ and even more from the distribution mean, in the data on mechanical properties of meteorites in the literature (Svetsov et al. 1995; Tsvetkov and Skripnik 1991; Popova et al. 2011; Flynn et al. 2018). To a large extent, it reflects the degree of imperfection of the meteoritic material, the used experimental techniques and skills of the researchers. More than this, meteorites are often mechanically heterogeneous on a macroscopic scale due to their bombardment history-including the final fall through the atmosphere. Such a level of uncertainty in the initial mechanical properties of asteroids makes it challenging to model their fracture behaviour during 
atmospheric entry. The Chelyabinsk meteorite is quite an exceptional case: a large number of observations (more than 400 videos) of its fall make it possible to obtain more accurate estimations of its mechanical properties (Popova et al. 2013). Additional detail studies of the deformation and fracture behaviour of the Chelyabinsk chondrite under compression and tension should help researches to simulate the entrance of the meteoroid into the Earth's atmosphere (Gorkavyi et al. 2019; Dudorov and Mayer 2014) followed by a collision with the Earth surface.

Here, we study the mechanical properties of Chelyabinsk LL5 chondrite under uniaxial compression and diametral compression/indirect tension tests. These findings will expand our knowledge about the mechanical properties of a meteoritic material that allows one to determine the place of the Chelyabinsk meteorite among other meteorites in terms of its mechanical characteristics. There are just a few measurements of the strength of LL type chondrites (Flynn et al. 2018). As far as we know, we have measured the tensile strength of the Chelyabinsk chondrite for the first time.

\section{Materials and Methods}

\subsection{Sample Preparation}

Two similar fragments of the Chelyabinsk meteorite which have been found during the expedition headed by professor A.E. Dudorov in February 2013 near the Emanzhelinka township (Chelyabinsk region, Russia) were used in this work (Fig. 1a). The fragments were cut into pieces having $3 \mathrm{~mm}$ in thickness (Fig. 1b) using the diamond saw with water irrigation. The disk of the diamond saw diameter was $35 \mathrm{~mm}$ whereas its thickness was $0.15 \mathrm{~mm}$. The observation was shown that the fragments were covered by a thin layer of fusion crust formed in the process of falling through the Earth's atmosphere, and there were a number of long cracks inside the pieces (Fig. 1b). Our samples had the light (or "main") lithography bounded by the melted layer. In the samples available to the authors, only small parts of their volume remain undamaged (Fig. 1b), so only small samples for mechanical testing could be prepared. They have been drilled by the diamond core bit with water irrigation from the regions of the pieces where the cracks were absent. Ten samples for each of the two groups were prepared for uniaxial and diametral compression tests, respectively. After that, the flat surfaces of the samples were abraded using abrasive papers. Finally, the samples have a cylindrical or tablet shape with a diameter of $3.3 \mathrm{~mm}$ and $1.65 \mathrm{~mm}$ in height (Fig. 1c).
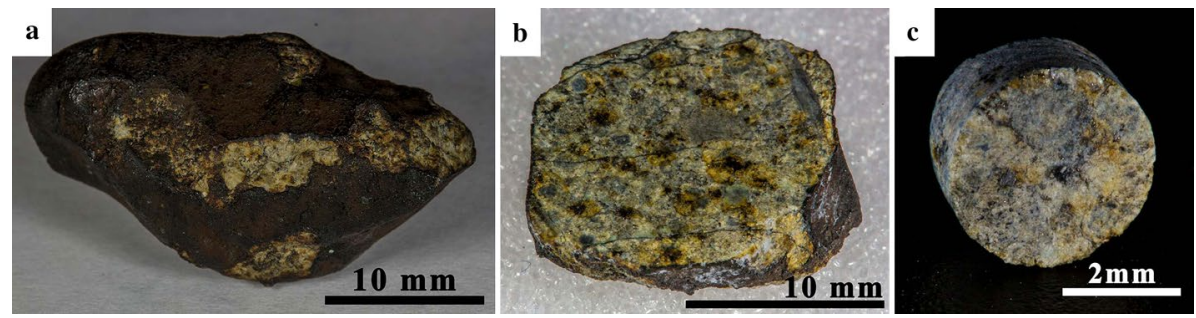

Fig. 1 The fragment of the Chelyabinsk meteorite: a general view; b pieces after cutting; c sample for mechanical testing 


\subsection{Microscopic Characterisation of Samples}

Canon photo microsystem (Canon D60 with Canon EF-S $60 \mathrm{~mm} \mathrm{f/2.8} \mathrm{Macro} \mathrm{USM} \mathrm{and}$ Canon Macrolite MT-24 EX) was used for imaging of the meteorites and the samples prior testing. Scanning electron microscope (SEM) JEOL-JEM 6390LV with accelerated voltage $20 \mathrm{kV}$ was used for characterisation of the fracture surfaces of the samples after the diametral compression test.

\subsection{Mechanical Testing}

Testing machine Shimadzu AGX-50kN was used for uniaxial and diametral compression at ambient temperature. The second mode (Brazilian disk experiment or indirect tension test) differs from the uniaxial one just in orientation, as it is shown in Fig. 2, but such special orientation creates dramatically different stress state inside the cylindrical sample (Yuan and Shen, 2017). Along the sample diameter, perpendicular to the loading direction, the stress state is very close to pure tension deformation conditions (Fig. 2). The rate of loading was $0.1 \mathrm{~mm} / \mathrm{min}$ in all tests. Processing of the results, including statistical analysis - average values and standard deviation measurements-was carried out by Trapezium, standard software for Shimadzu. The axial deformation of the sample was measured by the testing machine. The compression strength was considered as the maximal stress on the deformation curve, whereas the elastic modulus was calculated from the slope of the linear part of the deformation curve as a proportion between the stress and the strain. The diametral tensile stress and the diametral strain were calculated by equations $\sigma=2 \mathrm{~F} / \pi \mathrm{Dh}$ and $\varepsilon=(\Delta \mathrm{x} / \mathrm{D}) \times 100 \%$, respectively, where $\mathrm{F}$ is applied force, D-diameter of the sample, $\mathrm{h}-\mathrm{sample}$ height and $\Delta \mathrm{x}$ - the movement of the traverse (Fig. 2).

Fig. 2 The scheme of conventional compression test (a) and diametral compression/indirect tension test (b)
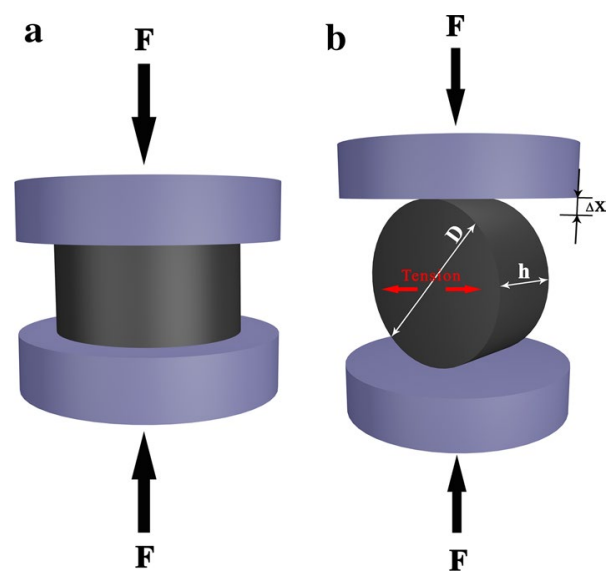


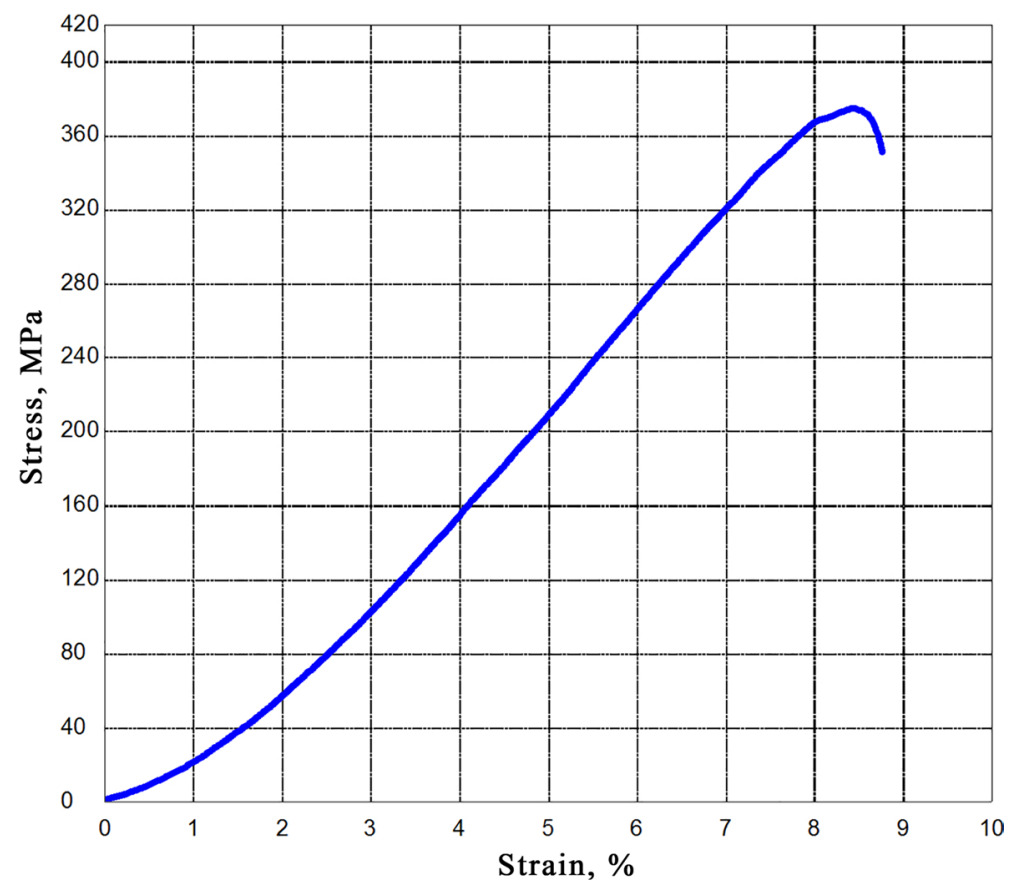

Fig. 3 The stress-strain curve of the sample of Chelyabinsk LL5 chondrite under uniaxial compression conditions

Table 1 The mechanical properties of Chelyabinsk LL5 chondrite under compression and tension

\begin{tabular}{llll}
\hline The scheme of deformation & Elastic modulus (GPa) & $\begin{array}{l}\text { Compression/tensile } \\
\text { strength (MPa) }\end{array}$ & $\begin{array}{l}\text { Total } \\
\text { deforma- } \\
\text { tion }(\%)\end{array}$ \\
\hline Uniaxial compression & $5.75 \pm 0.23$ & $372 \pm 10$ & $8.8 \pm 0.2$ \\
Diametral compression & $0.73 \pm 0.09$ & $8.2 \pm 0.7$ & $1.1 \pm 0.1$ \\
\hline
\end{tabular}

\section{Results}

\subsection{Mechanical Behaviour}

Most of the closest to the average stress-strain curve of the Chelyabinsk LL5 chondrite under compression (Fig. 3) can be approximated by the straight line. This fact allows us to assume that the deformation of the Chelyabinsk chondrite is elastic under compression. The mechanical properties of Chelyabinsk chondrite under compression are given in Table 1. The elastic modulus, which is the coefficient of proportionality between stress and strain, is $5.75 \pm 0.23 \mathrm{GPa}$. The compression strength (see Fig. 3) is $372 \pm 10 \mathrm{MPa}$, and the total compression deformation is $8.8 \pm 0.2 \%$.

The trend closest to the average stress-strain curve of Chelyabinsk LL5 chondrite under diametral compression is shown in Fig. 4. Clearly, the form of the curve here also as straight as it takes place under compression. Hence, the Chelyabinsk chondrite is deformed 


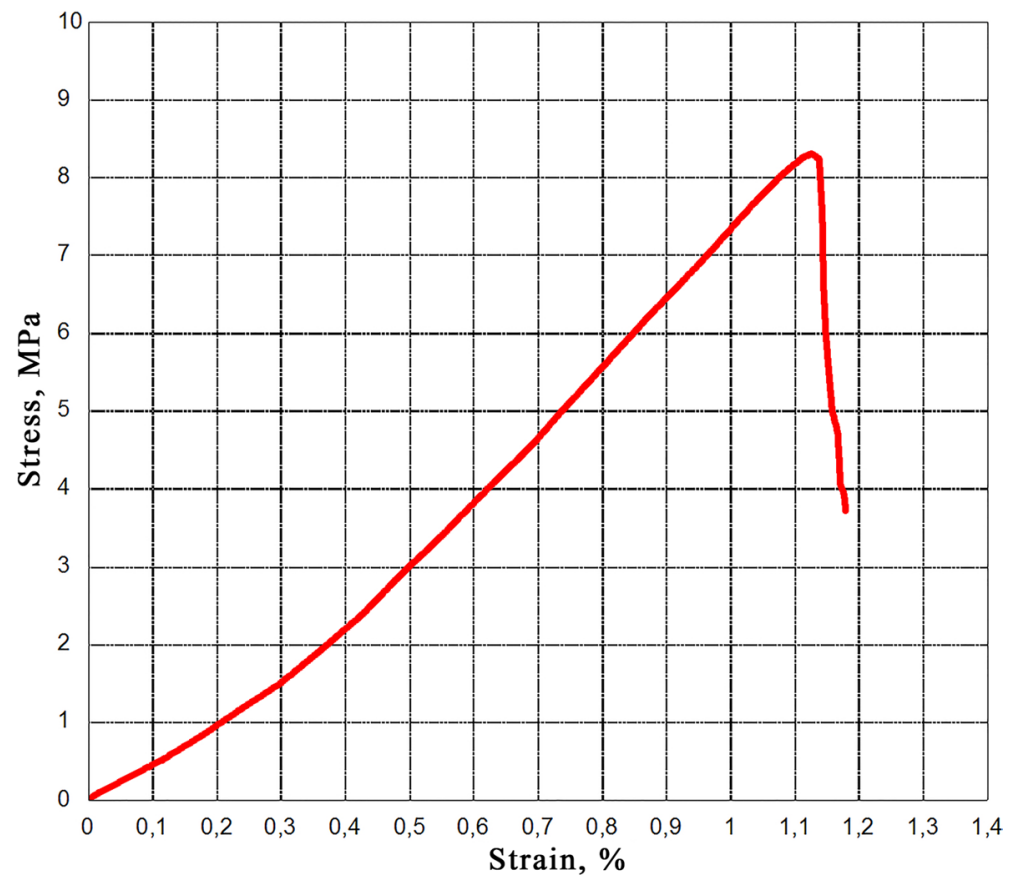

Fig. 4 The stress-strain curve of the sample of Chelyabinsk LL5 chondrite under diametral compression/ indirect tension conditions

in an elastic regime both at compression and tension conditions. The mechanical characteristics of the Chelyabinsk meteorite under the diametral compression/indirect tension test are also given in Table 1. The elastic modulus is $0.73 \pm 0.09 \mathrm{GPa}$. It should be noted that the elastic modulus under diametral compression characterized by the ratio between the stress and the strain that are perpendicular to each other in this case. Therefore, its value cannot be compared with the elastic modulus, which was obtained from the compression test. The diametral tensile strength is $8.2 \pm 0.7 \mathrm{MPa}$, and the total tensile deformation is $1.1 \pm 0.1 \%$.

\subsection{2 Fracture Behaviour}

The abrupt changing of the deformation curve trend at the end of the test (dropping of the stress in Figs. 3 and 4) corresponds to the failure of the sample. At the uniaxial compression loading, the fracture occurs gradually (Fig. 3) and the samples were crumbling into small pieces, whereas during the diametral compression test, the sample separates into two equal parts along the loading plane (Fig. 2) that happens abruptly (Fig. 4). Observation of the fracture surfaces of pieces of the sample after its diametral compression test was shown that they are quite rough, and fracture behaviour corresponds to cleavage (Fig. 5a). Such behaviour can be characterised as brittle. There are many light inclusions inside the meteoritic material (Fig. 5a, b), which are apparently a mixture of Fe, Ni metal blebs (Dudorov et al. 2016) with some sulphides additions. The size of the light inclusions is ranged from 10 to $100 \mu \mathrm{m}$ (Fig. 5b). The fracture at our experiments occurred both between the grains 

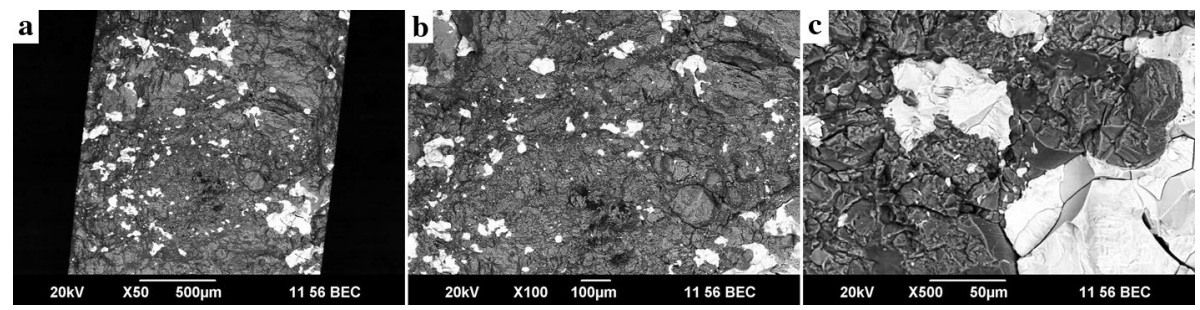

Fig. 5 The fracture surface of the sample of Chelyabinsk LL5 chondrite under diametral compression/indirect tension test: a-general view (X50 magnification); b-light metallic inclusion in the meteoritic material (X100); c-crack distribution in the sample (X500)

and into the light inclusions (Fig. 5c). Furthermore, the layered structure of part of the samples (likely barred chondrules) has been observed (Fig. 6a). There are a number of undamaged melted layers alternated with the rock layers like structure where the cracks are contained (Fig. 6b). It seems clear that the layered structure had formed before the experiment, while the cracks are the effect of sample loading. The width of the undamaged layer is $10 \mu \mathrm{m}$, whereas the width of another layer is in the range of 10-20 $\mu \mathrm{m}$ (Fig. 6c).

\section{Discussion}

\subsection{Deformation and Fracture Behaviour of the Chelyabinsk Chondrite}

Our study has shown that the deformation and fracture behaviour of pieces of the Chelyabinsk meteorite is brittle. The deformation was elastic on the entire stage of loading under both compression and tension conditions (Figs. 3 and 4, respectively). Also, the samples fractured almost immediately just the maximal load is achieved, especially under diametral tension conditions. The fracture occurred both between the grains and into the light inclusions (Fig. 5c). The strength of the Chelyabinsk chondrite under compression is more than 45 times greater as compared with tension: $372 \pm 10 \mathrm{MPa}$ and $8.2 \pm 0.7 \mathrm{MPa}$, respectively. The former value is much higher than the one reported by Galimov et al. (2013), and the latter is the first reported for Chelyabinsk (see Table 1). Such big differences between the compression and tensile strength are usual for a number of very different materials. They are maximal for brittle materials and lower for ductile in the case when the fracture occurs under compression conditions. For example, the compression strength is more than
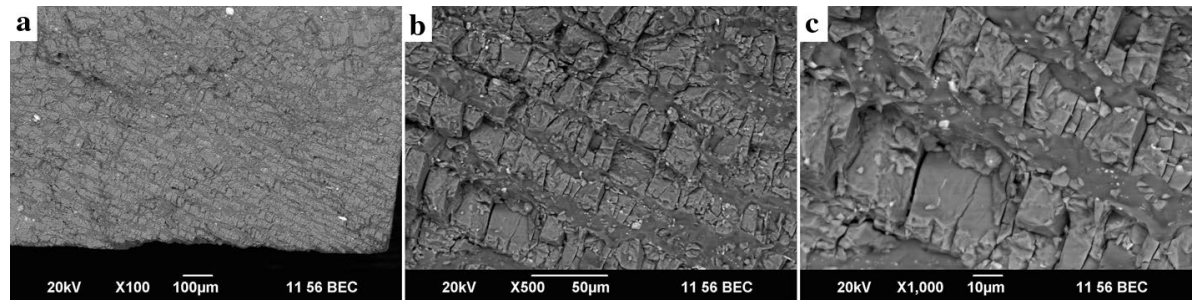

Fig. 6 The layered structure on the fracture surface of the sample of Chelyabinsk LL5 chondrite under diametral compression/indirect tension test: $\mathbf{a}-$ general view at X100 magnification; $\mathbf{b}-\mathrm{X} 500$ magnification; c-X1000 magnification 
11 times greater than the tensile strength of aluminium oxide (Shackelford et al. 2001). It is caused by the different types of stresses and their distribution into the material. The large difference for Chelyabinsk chondrite is pointed to the prominent role of the defects in its deformation and fracture behaviour (Popova et al. 2011). The difference given for the stony meteorites (compressive strength $217 \pm 134 \mathrm{MPa}$ and tensile strength of $30 \pm 17 \mathrm{MPa}$ ) is lower than for Chelyabinsk LL5 chondrite both in the present research and the other measurements (Popova et al. 2013; Svetsov et al. 1995; Tsvetkov and Skripnik 1991; Popova et al. 2011). However, the large standard deviation of the values for stony meteorites makes such a comparison purely conditional. The lower compression strength of the Chelyabinsk meteorite (64.0 MPa) given in Popova et al. (2013), in contrast with our findings $(372 \pm 10 \mathrm{MPa})$, may be caused by the size of the testing sample. The cuboids sample having size $10 \times 10 \mathrm{~mm}$ and $20 \mathrm{~mm}$ in height was tested in (Popova et al. 2013), whereas the cylindrical samples with the diameter $3.3 \mathrm{~mm}$ and $1.65 \mathrm{~mm}$ in height were used in this work. It is possible that such a relatively big sample as in Popova et al. (2013) may contain long cracks, as shown in Fig. 1a, that could lead to a lower strength of the sample.

A lot of cracks are observed between the grains (Fig. 5b). It indicates the presence of weak bonds between the grains. Such tiny cracks (usually below $100 \mu \mathrm{m}$ ) into the fragments of the Chelyabinsk meteorite are stress concentrators. At the places of their localization, the dangerous cracks subsequently appear that leads to fracture of the entire sample and significantly decrease its tensile strength under the mechanical testing. In addition, the fracture occurred into the light inclusions under mechanical testing (Fig. 5c). It has been shown that the light inclusions are metallic phase consisting mainly of Fe and $\mathrm{Ni}$ (Dudorov et al. 2016). Brittle cracks propagated into $\mathrm{Fe}$, Ni blebs which previously had been fracture free. The compressive strength of the specimens is not decreasing significantly since the wedging stress near the tiny crack tip is much lower under compression in contrast with tension due to the crack growth suppression.

\subsection{The Shape of the Chelyabinsk Fireball}

It is well known that fragmentation of the meteorite Chelyabinsk began at an altitude of about $30 \mathrm{~km}$ above the Earth's surface (Popova et al. 2013; Dudorov et al. 2016). The air density at this height can be estimated by the barometric formula (Emmert 2015) and is about $\rho_{\mathrm{g}} \approx 0.05 \mathrm{~kg} / \mathrm{m}^{3}$ (Dudorov and Mayer 2014). The force acting on the falling meteoroid can be estimated using the equation (Landau and Lifshitz 1987):

$$
\mathrm{F}=0.5 \mathrm{C}_{\mathrm{d}} \mathrm{SV}^{2} \rho_{\mathrm{g}},
$$

where the drag coefficient for the spherical shape $\mathrm{C}_{\mathrm{d}} \sim 0.9$ and $\mathrm{C}_{\mathrm{d}}=1.0$ (Landau and Lifshitz 1987) for near-cube shape, $S$ is the meteoroid surface area, and $V$ is its velocity. The maximal stress is located near the front surface of the meteoroid. For the stress acting on the meteoroid, one can obtain with Eq. (1):

$$
\sigma=0.5 \mathrm{C}_{\mathrm{d}} \mathrm{V}^{2} \rho_{\mathrm{g}}
$$

The meteoroid entry velocity into the Earth atmosphere is about $\mathrm{V} \approx 19 \mathrm{~km} / \mathrm{s}$ (Dudorov et al. 2016). Hence, the stress at the initial stage of the fragmentation process for spherical fireball (Fig. 7a) is at most $\sigma \approx 8 \mathrm{MPa}$, while for cuboids fireball it is no more than $9 \mathrm{MPa}$ (Fig. 7b). These values are significantly lower than the experimental compression strength of the Chelyabinsk chondrite $(372 \pm 10 \mathrm{MPa})$ but are close 
Fig. 7 The schemes of stress acting on the meteoroid during its penetrating into the Earth atmosphere: a-spherical shape; b-cuboids shape

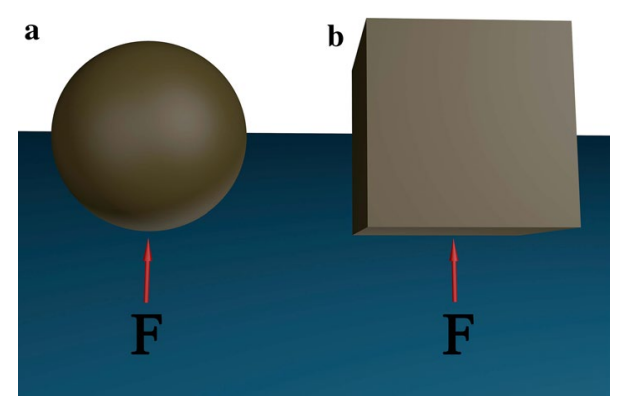

to its experimental tensile strength $(8.2 \pm 0.7 \mathrm{MPa})$. Hence, the stress state equivalent to those appearing at indirect tension conditions could have been taken place in the Chelyabinsk fireball when it was passing through the Earth atmosphere. So, it is very likely that the initial shape of the Chelyabinsk fireball was also spherical or ellipsoidal. In favour of this assumption also evidenced the fact that the Chelyabinsk fireball initially has separated into a few large parts (Dudorov and Mayer 2014) as it takes place at diametral compression (indirect tension) test, whereas the samples were crumbled into small pieces during the uniaxial compression test. The spherical shape of the Chelyabinsk fireball was also supposed in the work of Dudorov and Mayer (2014). The final form of the tiny ellipsoidal sample presented in Fig. 1a results from multiple fracture events of the initial large meteoroid, which was continuing its further disintegration after the initial break (Dudorov and Mayer 2014).

\section{Conclusions}

The mechanical testing of the Chelyabinsk LL5 chondrite under uniaxial compression and diametral compression/indirect tension test was shown that strength under compression was more than 45 times greater as compared with tension: $372 \pm 10 \mathrm{MPa}$ and $8.2 \pm 0.7 \mathrm{MPa}$, respectively. The deformation behaviour under compression and tension tests were similar, and it can be characterized as brittle. The compression strength of the Chelyabinsk meteorite was similar to many other stony meteorites, whereas its tensile strength was lower that may be caused by a large number of tiny cracks between the grains. The estimations were shown that if one supposes that the shape of the Chelyabinsk fireball was spherical or ellipsoidal, then the maximal shear stress $(\sim 7.78 \mathrm{MPa})$ is close to the experimental tensile strength $(8.2 \pm 0.7 \mathrm{MPa})$. Comparison of the experimentally measured tensile strength with the numerical evaluations leads us to conclude that the failure of the Chelyabinsk meteor occurred via tension rather than compression during its passage through the Earth's atmosphere.

Acknowledgements The reported study was supported by RSF, research Project No. 15-19-10007. Authors thank Mr. Craig Robert Walton and Dr. Ioannis Baziotis for their significant contribution to the improvement of the manuscript. The authors confirm that the data supporting the findings of this study is available within the article. 
Open Access This article is licensed under a Creative Commons Attribution 4.0 International License, which permits use, sharing, adaptation, distribution and reproduction in any medium or format, as long as you give appropriate credit to the original author(s) and the source, provide a link to the Creative Commons licence, and indicate if changes were made. The images or other third party material in this article are included in the article's Creative Commons licence, unless indicated otherwise in a credit line to the material. If material is not included in the article's Creative Commons licence and your intended use is not permitted by statutory regulation or exceeds the permitted use, you will need to obtain permission directly from the copyright holder. To view a copy of this licence, visit http://creativecommons.org/licenses/by/4.0/.

\section{References}

J. Borovicka, P. Spurný, P. Brown, P. Wiegert, P. Kalenda, D. Clark, L. Shrbený, The trajectory, structure and origin of the Chelyabinsk asteroidal impactor. Nature 503, 235-237 (2013). https://doi. org/10.1038/nature12671

S. Buhl, K. Wimmer, Trajectory projection of the Chelyabinsk superbolide and location of recorded meteorite finds. OpenStreetMap contributors (openstreetmap.org) (2013), www.meteorite-recon .com

A.E. Dudorov, D.D. Badyukov, S.N. Zamozdra, N.N. Gorkavyi, O.V. Eretnova, S.A. Khaibrakhmanov, A.E. Mayer, S. Taskaev, Meteoroid, bolide and meteorite «Chelyabinsk». Mater. Sci. Forum 845, 273-284 (2016). https://doi.org/10.4028/www.scientific.net/MSF.845.273

A.E. Dudorov, A.E. Mayer, Dynamics and fracture of Chelyabinsk meteoroid in atmosphere. Vestnik ChelGU Phys. 19(1), 47-57 (2014). (in Russian)

J.T. Emmert, Thermospheric mass density: a review. Adv. Space Res. 56, 773-824 (2015)

V.V. Emel'yanenko, O.P. Popova, N.N. Chugai, M.A. Shelyakov, Yu.V. Pakhomov, B.M. Shustov, V.V. Shuvalov, E.E. Biryukov, Y.S. Rybnov, MY. Marov, L.V. Rykhlova, S.A. Naroenkov, A.P. Kartashova, V.A. Kharlamov, I.A. Trubetskaya, Astronomical and physical aspects of the Chelyabinsk event. Sol. Syst. Res. 47(4), 240-254 (2013). https://doi.org/10.1134/S0038094613040114

G.J. Flynn, G.J. Consolmagno, P. Brown, R.J. Macke, Physical properties of the stone meteorites. Chemie der Erde. 78, 269-298 (2018). https://doi.org/10.1016/j.chemer.2017.04.002

E.M. Galimov, V.P. Kolotov, M.A. Nazarov, Yu.A. Kostitsyn, I.V. Kubrakova, N.N. Kononkova, I.A. Roshchina, V.A. Alexeev, L.L. Kashkarov, D.D. Badyukov, V.S. Sevast'yanov, Analytical results for the material of the Chelyabinsk meteorite. Geochem. Int. 51(7), 580-598 (2013). https://doi. org/10.1134/S0016702913070100

N. Gorkavyi, A. Dudorov, S. Taskaev (Eds.) Chelyabinsk Superbolide. Springer, Switzerland, 2019. https:// doi.org/10.1007/978-3-030-22986-3

S.S. Grygorian, F.S. Ibodov, S.I. Ibadov, Physical mechanism of Chelyabinsk superbolide explosion. Sol. Syst. Res. 47(4), 268-274 (2013). https://doi.org/10.1134/S0038094613040151

J.D. Hogan, J. Kimberley, K. Hazelei, J. Plescia, K.T. Ramesh, Dynamic behavior of an ordinary chondrite: The effects of microstructure on strength, failure and fragmentation. Icarus 260, 308-319 (2015). https ://doi.org/10.1016/j.icarus.2015.07.027

D. Kaeter, M.A. Ziemann, U. Bottger, I. Weber, L. Hecht, S.A. Voropaev, A.V. Korochantsev, A.V. Kocherov (2017) The Chelyabinsk meteorite: New insights from a comprehensive electron microscopy and Raman spectroscopy study with evidence for graphite in olivine of ordinary chondrites. Meteorit. Planet. Sci., https://doi.org/10.1111/maps.13027

T. Kohout, M. Gritsevich, V.I. Grokhovsky, G.A. Yakovlev, J. Haloda, P. Halodova, R.M. Michallik, A. Penttilä, K. Muinone, Mineralogy, reflectance spectra, and physical properties of the Chelyabinsk LL5 chondrite-Insight into shock-induced changes in asteroid regoliths. Icarus 228, 78-85 (2014). https:// doi.org/10.1016/j.icarus.2013.09.027

J. Kimbereley, K.T. Ramesh, The dynamic strength of an ordinary chondrite. Meteorit. Planet. Sci. 46(11), 1653-1669 (2011). https://doi.org/10.1111/j.1945-5100.2011.01254

L.D. Landau, E.M. Lifshitz, Fluid Mechanics (Volume 6 of A Course of Theoretical Physics) Pergamon Press, Oxford, 1987

J.D. Morgan, J. Kimberley, K. Hazelei, J. Plescia, K.T. Ramesh, Dynamic behavior of an ordinary chondrite: the effects of microstructure on strength, failure and fragmentation. Icarus 260, 308-319 (2015)

A. Morlok, A. Bischoff, M. Patzek, M. Sohn, H. Hiesinger, Chelyabinsk-a rock with many different (stony) faces. Icarus 284, 431-442 (2017)

O.P. Popova, P. Jenniskens, V. Emel'yanenko, A. Kartashova, E. Biryukov, S. Khaibrakhmanov, V. Shuvalov, Yu Rybnov, A. Dudorov, V.I. Grokhovsky, D.D. Badyukov, Q.-Z. Yin, P.S. Gural, J. Albers, M. 
Granvik, L.G. Evers, J. Kuiper, V. Kharlamov, A. Solovyov, Y.S. Rusakov, S. Korotkiy, I. Serdyuk, A.V. Korochantsev, M.Y. Larionov, D. Glazachev, A.E. Mayer et al., Chelyabinsk airburst, damage assessment. Meteorite recovery, and characterization. Science 342, 1069-1073 (2013). https://doi. org/10.1126/science. 1242642

O. Popova, J. Borovička, W.K. Hartmann, P. Spurný, E. Gnos, I. Nemtchinov, J.M. Trigo Rodríguez, Very low strength of interplanetary meteoroids and small asteroids. Meteorit. Planet. Sci. 46, 1525-1550 (2011). https://doi.org/10.1111/j.1945-5100.2011.01247

K. Righter, P. Abell, D. Agresti, E.L. Berger, A.S. Burton, J.S. Delaney, M.D. Fries, E.K. Gibson, M.K. Haba, R. Harrington, G.F. Herzog, L.P. Keller, D. Locke, F.N. Lindsay, T.J. McCoy, R.V. Morris, K. Nagao, K. Nakamura-Messenger, P.B. Niles, L.E. Nyquist, J. Park, Z.X. Peng, C.-Y. Shih, J.I. Simon, I.I.I. Swisher, C.C. Tappa, M.J. Turrin, B.D. Zeigler, R.A, Mineralogy, petrology, chronology, and exposure history of the Chelyabinsk meteorite and parent body. Meteorit. Planet. Sci. 50(10), 17901819 (2015). https://doi.org/10.1111/maps.12511

V.V. Svetsov, I.V. Nemtchinov, A.V. Teterev, Disintegration of large meteoroids in Earth's atmosphere: theoretical models. Icarus 116, 131-153 (1995). https://doi.org/10.1006/icar.1995.1116

J.F. Shackelford, et. al. in "Frontmatter" Materials Science and Engineering Handbook Ed, ed. by J.F. Shackelford \& W (CRC Press LLC, Alexander Boca Raton, 2001)

V.I. Tsvetkov, A.Y. Skripnik, Atmospheric fragmentation of meteorites according to strength theory. Sol. Syst. Res. 25, 273-279 (1991)

R. Yuan, B. Shen, Numerical modelling of the contact condition of a Brazilian disk test and its influence on the tensile strength of rock. Int. J. Rock Mech. Min. Sci. 93, 54-65 (2017)

Publisher's Note Springer Nature remains neutral with regard to jurisdictional claims in published maps and institutional affiliations. 